\title{
Adsorption of di-ethyl-phthalate from aqueous solutions with surfactant-coated nano/microsized alumina
}

\author{
Jidong $\mathrm{Li}^{\text {a,b }}$, Yali Shi ${ }^{\text {a }}$, Yaqi Cai ${ }^{\mathrm{a}, *}$, Shifen Mou ${ }^{\mathrm{a}}$, Guibin Jiang ${ }^{\mathrm{a}}$ \\ a State Key Laboratory of Environmental Chemistry and Ecotoxicology, Research Center for Eco-Environmental Sciences, \\ Chinese Academy of Sciences, P.O. Box 2871, Beijing 100085, China \\ ${ }^{\mathrm{b}}$ General Research Institute for Non-ferrous Metals, Beijing 100088, China
}

Received 19 April 2007; received in revised form 13 September 2007; accepted 24 September 2007

\begin{abstract}
The different adsorption characteristics of sodium dodecyl sulfate (SDS)-coated nano/microsized alumina systems for di-ethyl-phthalate (DEP) were studied in this paper. The investigations were carried out in a series of batch experiments under different solution conditions such as SDS concentration, $\mathrm{pH}$ value, ionic strength and temperature. Freundlich equation was used for evaluating the influences of various experimental conditions on the adsorption process. The Freundlich constants indicated that SDS-coated nanosized alumina had a greater adsorption affinity and capacity than SDS-coated microsized alumina; kinetics study results of pesudo-second-order rate equation proved that SDS-coated nanosized alumina had a higher adsorption rate. The experimental results showed that SDS-coated nanosized alumina was more effective and suitable for adsorbing DEP in water; furthermore, the feasibility of this method can also be a useful guidance for adsorbing other hydrophobic organic contaminants in water.
\end{abstract}

(C) 2007 Elsevier B.V. All rights reserved.

Keywords: Di-ethyl-phthalate; Sodium dodecyl sulfate; Alumina; Nanosize; Microsize

\section{Introduction}

Surfactant present in aqueous solution can form stable selfaggregates (micelles) when the surfactant concentration is above the critical micelle concentration (CMC). The formed micelles can incorporate hydrophobic organic compounds (HOCs), which can increase the solubility of these compounds apparently. Surfactant can also form self-aggregates at the solid surface such as alumina, silica and ferric oxyhydroxides surface. In recent years, adsorption of surfactant at solid-liquid interface has been studied extensively [1-8].

Alumina is a classical adsorbent to study adsorbing anionic surfactants onto its positively charged surface since it possesses high surface area. Many technical applications based on surfactant adsorbed on alumina had led to many theoretical studies and the information obtained was very useful for improving the efficiency of adsorbing HOCs in water [9-12]. Compared with adsorbing HOCs in water with alumina directly, alumina coated

\footnotetext{
* Corresponding author. Tel.: +86 1062849182 ; fax: +86 1062849239.

E-mail address: caiyaqi@ rcees.ac.cn (Y. Cai).
}

with surfactant would have bigger adsorption amounts. Generally, the alumina surface is hydrophilic and has low adsorption affinity for organic compounds; however, when it is treated with sodium dodecyl sulfate (SDS), alumina will acquire high adsorption capability for HOCs. The reason is due to the fact that when the solution $\mathrm{pH}$ is below the point of zero charge (PZC) of alumina ( $\mathrm{pH} 8.5)$, the alumina surface is positively charged and anionic surfactants such as SDS molecules will adsorb onto the surface through the negative moiety sulfate. Due to the hydrophobic interactions of micelles formed on alumina surface, the HOCs escape from aqueous phase and become concentrated in the microscopic hydrophobic phase [9,11]. Sun and Jaffe [9] compared the efficiency of adsorbing phenanthrene from water using alumina treated with three kinds of dianionic surfactants and the results showed that dianionic surfactants adsorbed on alumina were more effective phase for adsorbing phenanthrene; furthermore, the apparent distribution coefficient of phenanthrene onto the solid phase was increased up to 3 orders of magnitude. Gawade et al. [12] investigated the different effects of removing herbicide from wastewater using alumina and SDScoated alumina and the experimental results indicated that the latter had obvious enhancement in adsorbing herbicide. To date, 
many works have shown that alumina treated with anionic surfactant can enhance its adsorption capacity for HOCs. However, in most case, the size of applied alumina was microsized and systematic studies on adsorbing HOCs using nanosized alumina modified with anionic surfactant are scanty.

Nanosized alumina is a kind of new functional material and it has attracted extensive attentions because of its specific physical and chemical properties such as high surface area, absence of internal diffusion resistance and high surface binding energy in recent years $[13,14]$. Compared with the traditional microsized particle supports, nanosized carriers possess quite good adsorption performance [15]. According to the characteristics of nanosized alumina, it may be assumed that SDS-coated nanosized alumina should have higher adsorption capacity and rate for HOCs than SDS-coated microsized alumina. To our knowledge, the study in this field has not been reported so far.

In present study, di-ethyl-phthalate (DEP) was selected as model HOC which is widely used as plasticizers in many daily used products such as plastic, pesticide, paint and cosmetic. DEP can be leached from the above-mentioned products and find a way to various environmental waters $[16,17]$. Some phthalates (the so-called endocrine disruptor compounds, EDC) can cause endocrine system disorder, produce carcinogenic effects and afflict the development of reproductive system [18,19]. Therefore, the studies on the adsorbing DEP in water have important significance.

In this paper, we investigated the different adsorption behaviors and characteristics of SDS-coated nano/microsized alumina for DEP. Mixed hemimicelles were prepared by adsorbing SDS on nano/microsized alumina surface and the predominant experimental factors affecting the adsorption were studied. The research results provided a useful guidance for removing DEP in water and corresponding application in wastewater treatment.

\section{Experimental}

\subsection{Materials}

All reagents were of analytical grade and used as supplied. SDS was obtained from Shanghai Reagent Corporation (Shanghai, China) and its CMC was $8 \mathrm{mM}$; DEP was purchased from Beijing Chemicals Corporation (Beijing, China) and their physicochemical properties were listed in Table 1. A stock solution containing 0.1 M DEP was prepared in methanol. Micro/nanosized alumina ( $\gamma$-form) was supplied by Sigma Corporation (Steinheim, Germany) and Luming Nanosized
Table 2

Physical properties of nano/microsized alumina

\begin{tabular}{lcc}
\hline Physical properties & Microsized alumina & Nanosized alumina \\
\hline Surface area $\left(\mathrm{m}^{2} / \mathrm{g}\right)$ & 155 & 235 \\
PZC & 8.5 & 8.2 \\
Mean particle diameter & $100 \mu \mathrm{m}$ & $30 \mathrm{~nm}$ \\
Density $\left(\mathrm{g} / \mathrm{cm}^{3}\right)$ & 3.97 & 3.65 \\
\hline
\end{tabular}

Materials Corporation (Dalian, China), respectively. Their physical properties were listed in Table 2. Ultrapure water (18.2 M $\Omega$ ) used in all experiments was prepared by a compact ultrapure water system from Barnstead (Iowa, USA).

\subsection{Methods}

The adsorption experiments were carried out in batch mode as follows: $0.5 \mathrm{~g}$ alumina was added to an aqueous solution containing $200 \mathrm{mg}$ SDS (except the SDS concentration experiments) and the total volume of aqueous suspension system was about $22 \mathrm{~mL}$ in a $250 \mathrm{~mL}$ glass vial; then the $\mathrm{pH}$ (the $\mathrm{pH}$ in all experiments was adjusted to 3 except the $\mathrm{pH}$ experiments) or the $\mathrm{NaCl}$ concentration (the $\mathrm{NaCl}$ concentration in all experiments was adjusted to $0.1 \mathrm{M}$ except the ionic strength experiments) was adjusted according to the experimental conditions; following the above step, the suspension was vibrated for $1 \mathrm{~h}$ for the formation of SDS micelles on alumina surface; then $25 \mathrm{mM}$ DEP were added and the total volume was set to $25 \mathrm{~mL}$ by adding some ultrapure water; at last, the suspension was vibrated $20 \mathrm{~h}$ continuously and a fraction of suspension was withdrawn followed by centrifuging at $4000 \mathrm{rpm}$ for $10 \mathrm{~min}$ at specified time. All experiments were run at $25 \pm 1{ }^{\circ} \mathrm{C}$ in a water bath (except the temperature conditions experiments). The concentration of SDS in supernatant was determined by Electrospray Ionization Mass Spectrometry (ESI-MS, API 3200, ABI, USA) at $m / z 249.4$. The analysis was run in the "ESI (-) mode" and the operational parameters were used as follows: declustering potential, $-50 \mathrm{~V}$; entrance potential, $-4.0 \mathrm{~V}$; collision cell entrance potential, $-12 \mathrm{~V}$; collision energy, $-52 \mathrm{~V}$; collision cell exit potential, $-57.2 \mathrm{~V}$; source temperature, $350{ }^{\circ} \mathrm{C}$ and maximal accumulation time, $50 \mathrm{~ms}$. The DEP was determined by HPLC with a UV detector (AD25, Dionex, USA) and the detection wavelength was $226 \mathrm{~nm}$. The amounts of SDS or DEP adsorbed were calculated from the difference between the total amount added to the suspension and the amount remained in solution.

Table 1

Physicochemical properties of SDS and DEP

\begin{tabular}{|c|c|c|c|c|c|}
\hline Name & Abbreviation & Molecular structure & Molecular formula & Molecular weight & Water Solubility $(\mathrm{g} / \mathrm{L})$ \\
\hline Sodium dodecyl sulfate & SDS & $\mathrm{CH}_{3}\left(\mathrm{CH}_{2}\right) 10 \mathrm{CH}_{2} \mathrm{O}^{\prime}$ & $\mathrm{C}_{12} \mathrm{H}_{25} \mathrm{SO}_{4} \mathrm{Na}$ & 288 & 15 \\
\hline Di-ethyl-phthalate & DEP & & $\mathrm{C}_{12} \mathrm{H}_{22} \mathrm{O}_{4}$ & 222 & 1.1 \\
\hline
\end{tabular}



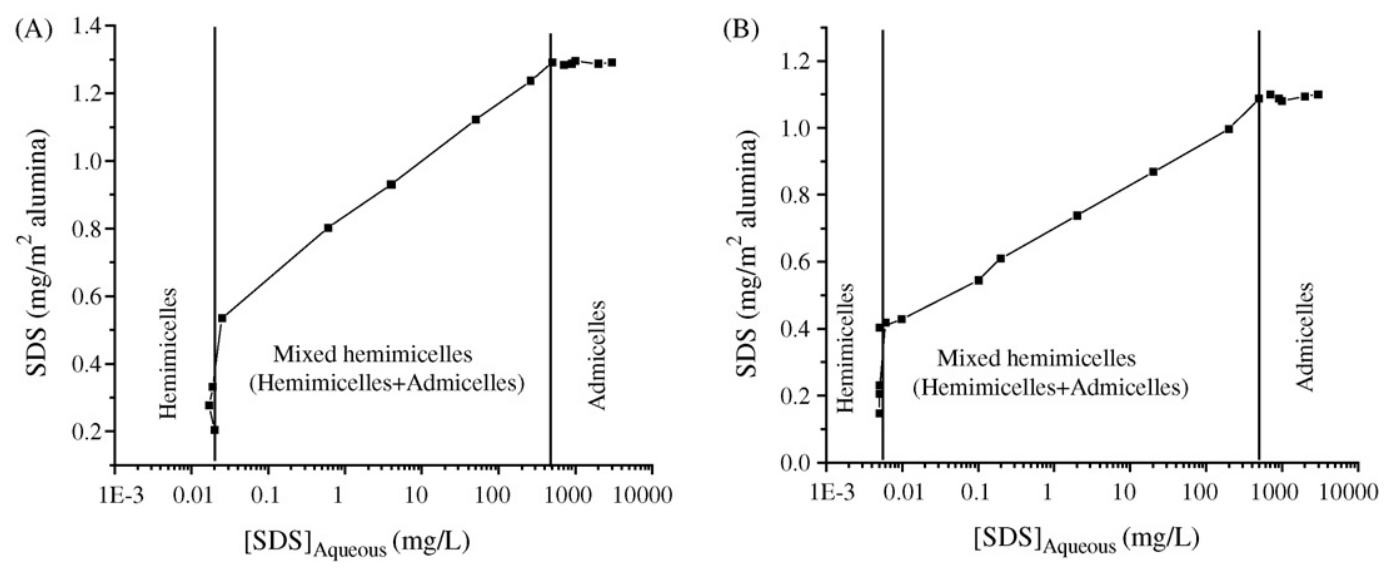

Fig. 1. The adsorption of SDS on alumina as a function of SDS concentration at pH 3.0: (A) nanosized alumina and (B) microsized alumina.

\section{Results and discussion}

\subsection{Adsorption isotherms of SDS on alumina}

The adsorption isotherms of SDS on nano/microsized alumina were useful for understanding the theory of adsorption process. Both adsorption isotherms in Fig. 1 indicated that, before a certain loading point reached (approximately 0.5 and $0.4 \mathrm{mg} / \mathrm{m}^{2}$ SDS for nanosized and microsized alumina, respectively), nearly no SDS was left in the aqueous phase. With the increasing of SDS concentration, more SDS molecules began to adsorb on positively charged alumina surface through electrostatic attractions, then the isotherms showed a maximum adsorption amount (approximately 1.3 and $1.1 \mathrm{mg} / \mathrm{m}^{2}$ for nanosized and microsized alumina, respectively). After compensation of the alumina surface by SDS, the adsorption amounts became almost independent of the surfactant concentration and a plateau was observed. These adsorption isotherms did not fit conventional adsorption models (e.g. Langmuir) very well and might be explained as follows: adsorbing SDS on alumina surface was not a simple surface phenomenon but a multistep process involving different kinds of interactions. Generally, ionic surfactant adsorption isotherms on metal oxides can be divided into three regions [20]. In the first region the adsorbed surfactant molecules spread themselves on the alumina surface to form single layer coverage (Hemimicelles), probably through coulombic attractions between charged alumina surface and the oppositely charged surfactant head group. The second region involves hydrophobic and electrostatic interactions which are attributed to the formation of bilayers (admicelles). The structure of admicelles is characterized by a hydrophilic exterior and a hydrophobic interior. The process of solubilizing HOCs in hemimicelles and admicelles is termed as "adsolubilization". Both the above-mentioned regions are suitable for adsorption application. At the end of isotherm region (the third region) a plateau was observed, which was due to the fact that the overall surface charge of alumina was compensated and the repulsive interactions between the head groups of surfactants were unfavorable to further adsorbing SDS. As a result, SDS molecules began to form micelles in solution, which may result in the HOCs solubilizing into micelles in bulk solution again and this isotherm span was unsuitable for adsorption application.

\subsection{Effect of SDS concentration on the DEP adsorption}

Fig. 2 depicted the DEP adsorption on two kinds of alumina as a function of SDS amounts added at $\mathrm{pH}$ 3.0. It was found that DEP was hardly adsorbed onto alumina surface in the absence of SDS. In contrast, with the increasing SDS concentration, both the DEP adsorption amounts increased remarkably. The increase in adsorption can be explained by the gradual formation of mixed hemimicelles (hemimicelles and admicelles) on the alumina surface and then the adsorbed DEP amount increased gradually. The adsorption capacity of SDS-coated nanosized alumina began to exceed SDS-coated microsized alumina when the SDS amount added was above $25 \mathrm{mg}$. Maximum adsorption amount (about $53 \mu \mathrm{g} / \mathrm{m}^{2}$ ) was obtained for nanosized alumina when SDS added was in the range of $150-300 \mathrm{mg}$; about $28 \mu \mathrm{g} / \mathrm{m}^{2}$ was obtained for microsized alumina when SDS added was in the range of 175-210 mg. The experimental results showed obviously that adsorption amount had a relationship with alumina particle size.

The adsorption amount began to decrease when the SDS added exceeded $300 \mathrm{mg}$ for nanosized alumina and $210 \mathrm{mg}$ for microsized alumina. It can be explained by the fact that with more SDS added the SDS molecules began to form micelles in

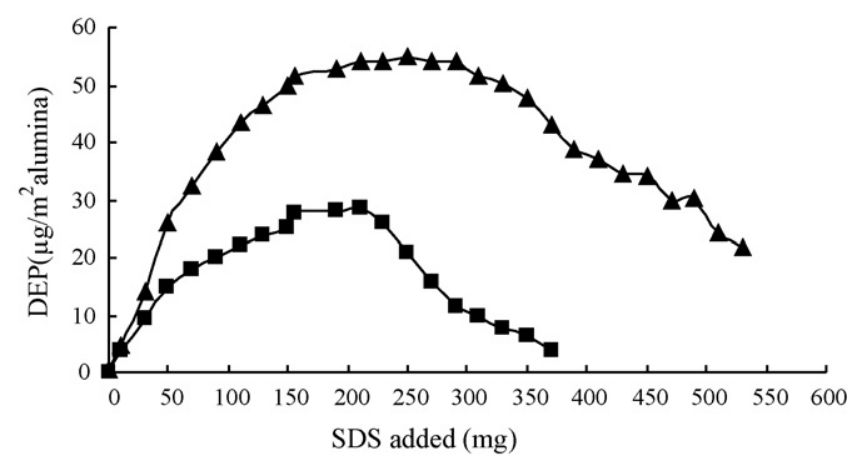

Fig. 2. The adsorption of DEP $(1 \mathrm{mM})$ on nano/microsized alumina as a function of the SDS amounts added at pH 3.0: ( $\mathbf{\Lambda}$ ) nanosized alumina; (ם) microsized alumina. 
the bulk aqueous solution; moreover, the micelles make the DEP distribute into the bulk solution again. In this region the slope of nanosized alumina adsorption curve is flatter than that of microsized alumina, which indicated that the interactions between DEP- and SDS-coated nanosized alumina were stronger. As a result, it was more difficult for SDS-coated nanosized alumina to desorb DEP into aqueous solution.

\subsection{Equilibrium study}

Freundlich isotherm equation is widely used as empirical equation for adsorption study and derived by assuming a heterogeneous surface with a nonuniform distribution of adsorption heat over the surface [21]. The linearized form of the Freundlich model is given as follows

$\ln q_{\mathrm{e}}=\ln K_{\mathrm{F}}+\frac{1}{n} \ln C_{\mathrm{e}}$

where $q_{\mathrm{e}}$ is the amount adsorbed at equilibrium, $C_{\mathrm{e}}$ the equilibrium concentration of DEP in solution, $1 / n$ and $K_{\mathrm{F}}$ the constants for given adsorbate-adsorbent system, $K_{\mathrm{F}}$ can be used as an alternative measure of adsorption capacity, while $1 / n$ determines the adsorption affinity. A plot of $\ln q_{\mathrm{e}}$ versus $\ln C_{\mathrm{e}}$ will give the value of $1 / n$ and $K_{\mathrm{F}}$.

Fig. 3 shows Freundlich isotherms for adsorbing DEP on SDS-coated nano/microsized alumina. It can be seen that both the adsorption isotherms fit Freundlich isotherm equation well with the correlation coefficient $\left(R^{2}\right) 0.9927$ for nanosized alumina and 0.9918 for microsized alumina, respectively. The value of slope $(1 / n)$ for SDS-coated nano/microsized alumina was 1.12 and 0.857 , respectively, which revealed that SDS-coated nanosized alumina had stronger adsorption affinity than SDS-coated microsized alumina. The $K_{\mathrm{F}}$ value for two systems was 0.263 and 0.110 , respectively, which proved that SDS-coated nanosized alumina had higher adsorption capacity obviously.

\subsection{Adsorption kinetics study}

Quantifying the changes in adsorption kinetics with time requires an appropriate kinetic model equation. The pseudosecond-order rate equation shown as follows has been popularly

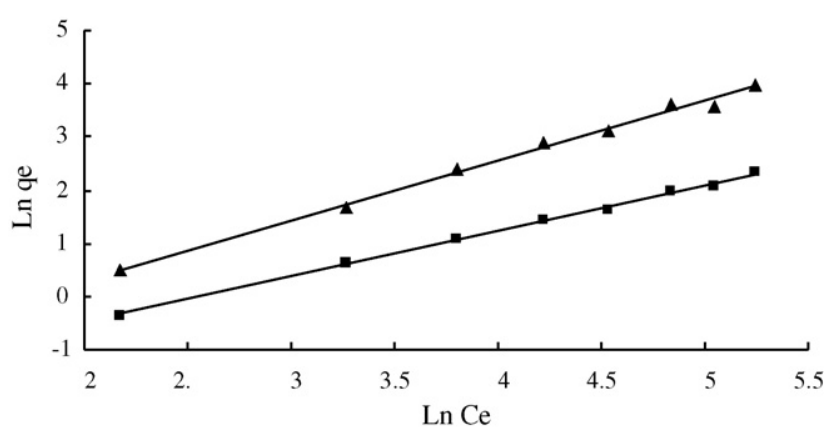

Fig. 3. Freundlich isotherms for the adsorption of DEP on nano/microsized alumina with $8 \mathrm{mg} / \mathrm{mL}$ SDS concentration at $\mathrm{pH}$ 3.0: (ム) nanosized alumina; (ם) microsized alumina.

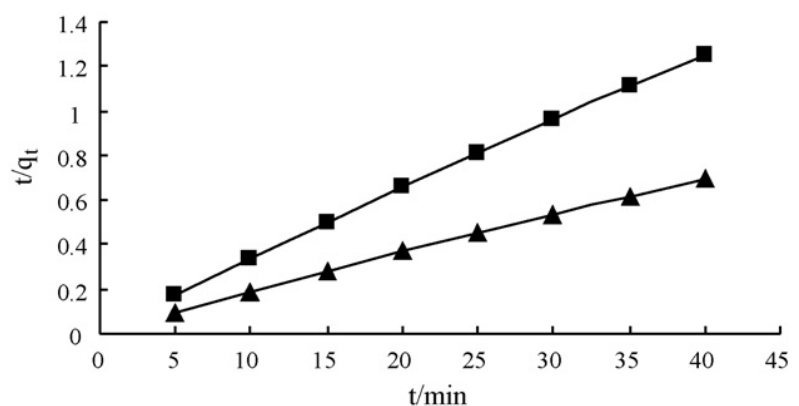

Fig. 4. Pseudo-second-order kinetic plot for adsorbing DEP $(1 \mathrm{mM})$ on nano/microsized alumina with $8 \mathrm{mg} / \mathrm{mL}$ SDS added and $0.5 \mathrm{~g}$ alumina in $25 \mathrm{~mL}$ solution at pH 3.0: (ム) nanosized alumina; (ם) microsized alumina.

applied to adsorption systems [22,23]:

$\frac{t}{q_{t}}=\frac{1}{K_{\mathrm{ad}} q_{\mathrm{e}}^{2}}+\frac{1}{q_{\mathrm{e}}} t$

where $K_{\mathrm{ad}}$ is the rate constant of adsorption, $q_{\mathrm{e}}$ the amount adsorbed at equilibrium and $q_{t}$ is the amount adsorbed at any time. As the $t \rightarrow 0$ the product $K_{\text {ad }} q_{\mathrm{e}}^{2}$ is actually the initial adsorption rate and can defined as

$h=K_{\mathrm{ad}} q_{\mathrm{e}}^{2}$

The initial adsorption rate $(h)$, the equilibrium adsorption amount $\left(q_{\mathrm{e}}\right)$ and the pseudo-second-order rate parameters $\left(K_{\mathrm{ad}}\right)$ can be calculated from the slope and intercept of plot of $t / q_{t}$ versus $t$ (Fig. 4). The values of constants were shown in Table 3. It can be seen that both the adsorption kinetics lines had a good fit for the pseudo-second-order kinetics model and the correlation coefficient $\left(R^{2}\right)$ of kinetics equation for nano/microsized alumina was 0.9959 and 0.9971 , respectively. The initial adsorption rate $(h)$, rate constant of adsorption $\left(K_{\mathrm{ad}}\right)$ and the equilibrium adsorption amount $\left(q_{\mathrm{e}}\right)$ of SDS-coated nanosized alumina adsorption equation were all higher than that of SDS-coated microsized alumina; specifically, the initial adsorption rate $(h)$ of SDS-coated nanosized alumina was about five times higher than that of the latter. As a result, it can be concluded that SDS-coated nanosized alumina has more excellent kinetic performance than SDS-coated microsized alumina.

\subsection{Effect of $p H$}

The $\mathrm{pH}$ of solution is one of the prime factors that drastically influence the adsorption amount of mixed hemimicelles system. In present study, the $\mathrm{pH}$ effect was observed by varying $\mathrm{pH}$ in the range of 1.6-9.2. It can be seen from Fig. 5 that both the adsorption amounts of mixed hemimicelles systems decreased obviously with the increasing of $\mathrm{pH}$; especially, when $\mathrm{pH}$ was

Table 3

Pseudo-second-order rate constants

\begin{tabular}{lllll}
\hline Adsorbent & $\begin{array}{l}K_{\mathrm{ad}}\left(\mathrm{m}^{2} /\right. \\
(\mu \mathrm{g} \min ))\end{array}$ & $q_{\mathrm{e}}\left(\mu \mathrm{g} / \mathrm{m}^{2}\right)$ & $\begin{array}{l}h(\mu \mathrm{g} / \\
\left.\left(\mathrm{m}^{2} \mathrm{~min}\right)\right)\end{array}$ & $R^{2}$ \\
\hline Nanosized alumina & 0.0530 & 53.02 & 148.90 & 0.9959 \\
Microsized alumina & 0.0315 & 28.58 & 25.73 & 0.9971 \\
\hline
\end{tabular}


Table 4

Freundlich constants and SDS adsorbed by alumina for different values of $\mathrm{pH}$, ionic strength and temperature

\begin{tabular}{|c|c|c|c|c|c|c|}
\hline \multirow[t]{2}{*}{ Parameter value } & \multicolumn{3}{|c|}{ Nanosized alumina } & \multicolumn{3}{|c|}{ Microsized alumina } \\
\hline & $1 / n$ & $K_{\mathrm{F}}$ & SDS adsorbed $(\mathrm{mg})^{\mathrm{a}}$ & $1 / n$ & $K_{\mathrm{F}}$ & SDS adsorbed (mg) \\
\hline \multicolumn{7}{|l|}{$\mathrm{pH}$} \\
\hline 3.8 & 1.12 & 0.263 & 96 & 0.857 & 0.110 & 52 \\
\hline 7.1 & 1.03 & 0.183 & 1.1 & 0.768 & 0.082 & 0.86 \\
\hline 9.2 & 0.87 & 0.121 & 0.12 & 0.702 & 0.067 & 0.08 \\
\hline 0.2 & 1.05 & 0.187 & 86 & 0.811 & 0.102 & 38 \\
\hline 0.3 & 0.97 & 0.157 & 65 & 0.756 & 0.085 & 30 \\
\hline 0.4 & 0.90 & 0.132 & 61 & 0.713 & 0.073 & 25 \\
\hline \multicolumn{7}{|l|}{ Temperature $\left({ }^{\circ} \mathrm{C}\right)$} \\
\hline 25 & 1.12 & 0.263 & 96 & 0.857 & 0.110 & 52 \\
\hline 40 & 1.05 & 0.213 & 87 & 0.808 & 0.096 & 48 \\
\hline
\end{tabular}

${ }^{a}$ The SDS adsorption amounts were calculated under the condition of a given SDS amount $(200 \mathrm{mg})$ after adsorption equilibrium.

above the PZC of alumina (about 8.5), the adsorption amount of SDS-coated nanosized alumina had a sharp decreasing. In the experimental $\mathrm{pH}$ range, the adsorption amount of SDS-coated nanosized alumina decreased from about 60 to $10 \mu \mathrm{g} / \mathrm{m}^{2}$ while from 40 to $0.5 \mu \mathrm{g} / \mathrm{m}^{2}$ for SDS-coated microsized alumina. These phenomena can be attributed to the fact that the alumina surface was positively charged when $\mathrm{pH}$ was below its PZC, so the anionic surfactant SDS molecules adsorbed to the alumina surface easily by a strong electrostatic attraction interactions. The interactions led to the formation of mixed hemimicelles on the alumina surface and DEP was adsorbed by the mixed hemimicelles through hydrophobic actions. With the $\mathrm{pH}$ value increasing, the positive charge of alumina surface reduced gradually and became negative charged when the $\mathrm{pH}$ was above its PZC. As a result, the SDS molecules desorbed from alumina surface gradually, which made the adsorption amount begin to decrease. It can also be proved by the SDS concentration changes listed in Table 4. The differences of two adsorption systems showed that the SDS-coated nanosized alumina always had the higher adsorption amounts than SDS-coated microsized alumina at the same $\mathrm{pH}$ condition. It may be attributed to the fact that the SDS-coated nanosized alumina had larger surface area and stronger adsorption affinity for DEP than SDS-coated

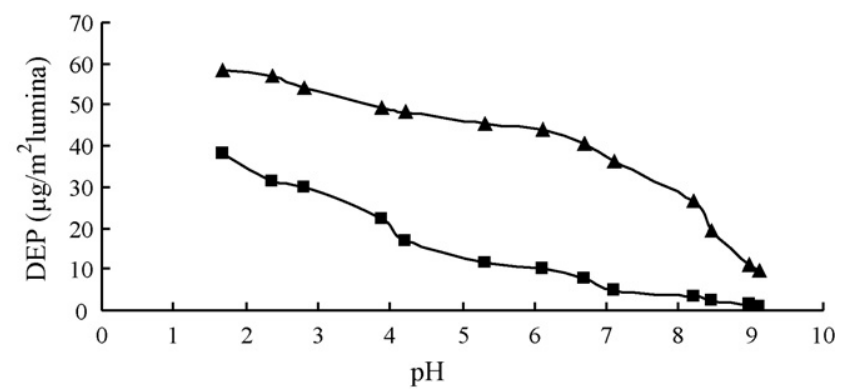

Fig. 5. Effect of $\mathrm{pH}$ on the adsorption of $1 \mathrm{mM}$ DEP on mixed hemimicelles consisting of $8 \mathrm{mg} / \mathrm{mL}$ SDS and $0.5 \mathrm{~g}$ alumina in $25 \mathrm{~mL}$ solution: ( $\mathbf{\Lambda}$ ) nanosized alumina; ( $\mathbf{\square})$ microsized alumina. microsized alumina. These observations can also be confirmed by Freundlich constants listed in Table 4.

\subsection{Effect of ionic strength}

Adsorption curves were obtained at $25^{\circ} \mathrm{C}$ and $\mathrm{NaCl}$ concentration ranged from 0.05 to $0.4 \mathrm{M}$. Fig. 6 shows that both the adsorption amounts of mixed hemimicelles systems decreased with increasing ionic strength. Using the linearized Freundlich equation, the coefficients for the adsorption were calculated and the results were summarized in Table 4 . The experimental results indicated that the role of electrostatic interactions in the adsorption process was significant and the competition of chloride ions for the alumina substrate existed obviously. As we know that in the first adsorption region the adsorbed surfactant molecules spread themselves on alumina surface to form single-layer coverage through coulombic attractions. As a result, the salt effect had a function to suppress the thickness of the electrical adsorption layer at the alumina surface. The changes of SDS adsorption amounts listed in Table 4 also shows that with the $\mathrm{NaCl}$ concentration increasing the SDS adsorbed by alumina began to

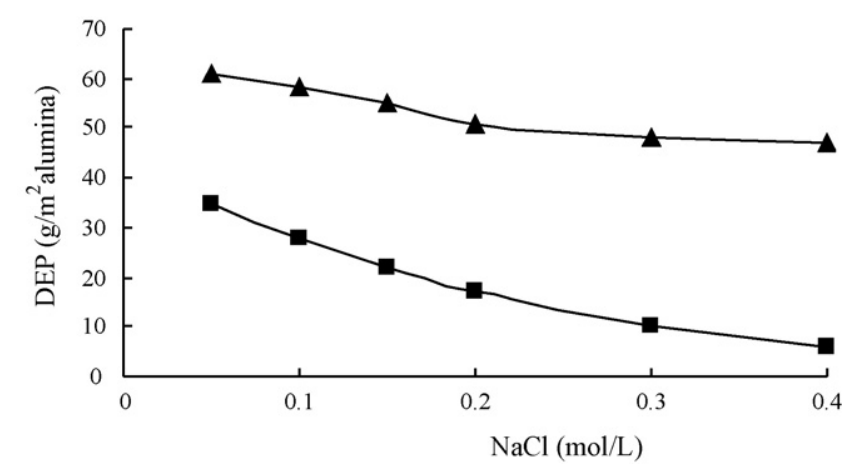

Fig. 6. Effect of ionic strength on the adsorption of $1 \mathrm{mM}$ DEP on mixed hemimicelles consisting of $8 \mathrm{mg} / \mathrm{mL}$ SDS and $0.5 \mathrm{~g}$ alumina in $25 \mathrm{~mL}$ solution: ( $\mathbf{\Delta})$ nanosized alumina; ( $\square$ microsized alumina. 


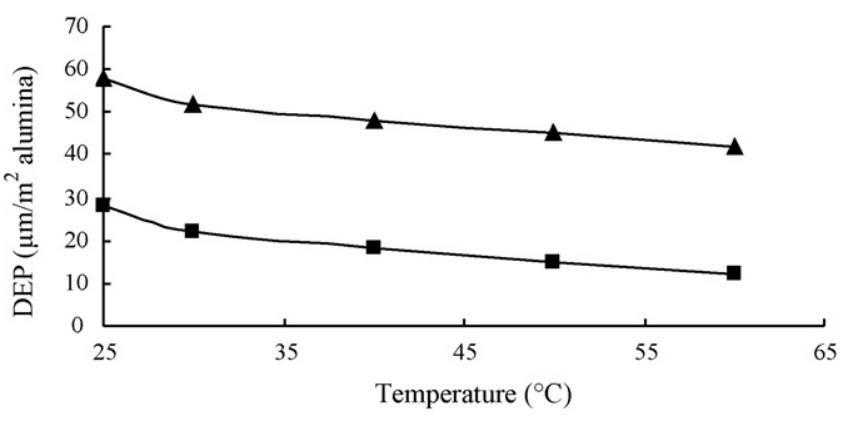

Fig. 7. Effect of temperature on the adsorption of $1 \mathrm{mM}$ DEP on mixed hemimicelles consisting of $8 \mathrm{mg} / \mathrm{mL}$ SDS and $0.5 \mathrm{~g}$ alumina in $25 \mathrm{~mL}$ solution: $(\boldsymbol{\Lambda})$ nanosized alumina; ( $\mathbf{\square})$ microsized alumina.

decrease obviously. According to the slope of two curves, Fig. 6 also shows that the ionic strength had more obvious effects on SDS-coated microsized alumina.

\subsection{Effect of temperature}

The effect of temperature on the DEP adsorption was investigated in the range $25-60^{\circ} \mathrm{C}$. It can be seen from Fig. 7 that both the DEP adsorption amounts of SDS-coated nano/microsized alumina systems decreased with increasing temperature. The decreased adsorption amounts suggested that the two adsorption systems were exothermic. With the increasing of temperature the adsorbate-adsorbent bonds were weakened and DEP had desorption trend from the solid phase to solution phase. It can also be proved by the changes of SDS adsorption amounts listed in Table 4. With the temperature increasing, the bond between alumina and SDS became weak and partial SDS molecules began to desorb from alumina surface. The experimental results were in accordance with the Freundlich constants listed in Table 4. Fig. 7 also shows that the two curves almost had same slope, which indicated that the temperature effects on two systems were similar.

\section{Conclusions}

The adsorption of SDS-coated nano/microsized alumina for DEP in water was studied in this paper. Due to some special properties of nanosized alumina (such as high surface area and surface binding energy), an excellent adsorption performance for DEP was obtained. The hydrophobic actions of mixed hemimicells played an important role in the adsorption process. The Freundlich equation gave a good fit to the experimental data and was applied to demonstrate the adsorption affinity and capacity in the $\mathrm{pH}$, ionic strength and temperature studies. The research results of pseudo-second-order rate equation proved that SDS-coated nanosized alumina had faster adsorption rate than SDS-coated microsized alumina. All the experimental results showed that nanosized alumina had better adsorption performance for its higher area surface and smaller granularity. Therefore, SDS-coated nanosized alumina mixed hemimicelles system is more effective and suitable for removing DEP in water.

\section{Acknowledgments}

This work was jointly supported by the National Natural Science Foundation of China (20475060, 20621703 and 20577058) and Major Research Program of Chinese Academy of Sciences (KZCX3-SW-432).

\section{References}

[1] T.M. Holsen, E.R. Taylor, Y.C. Seo, P.R. Anderson, Removal of sparingly soluble organic chemicals from aqueous solutions with surfactant-coated ferrikydrite, Environ. Sci. Technol. 25 (1991) 1585-1589.

[2] T.P. Goloub, L.K. Koopal, B.H. Bijsterbosch, Adsorption of cationic surfactants on silica. Surface charge effects, Langmuir 12 (1996) 3188-3194.

[3] K. Esumi, M. Matoba, Y. Yamanaka, Characterization of adsorption of quaternary ammonium cationic surfactants and their adsolubilization behaviors on silica, Langmuir 12 (1996) 2130-2135.

[4] K. Nagashima, F.D. Blum, Adsorption of sodium- $n$-decyl benzene sulfonate onto alumina: relationships between macro- and microscopic behavior, J. Colloid Interf. Sci. 214 (1999) 8-15.

[5] P.M. Jain, J.S. Smith, K.T. Valsaraj, Reusable adsorptions for dilute solution separation. 3. Sorption dynamics of phenanthrene on surfactant-modified alumina, Sep. Purif. Technol. 17 (1999) 21-30.

[6] S. L'opez, A. Senz, H.E. Gsponer, The effect of adsorbed sodium dodecylsulfate at the alumina-water interface on the luminescence quenching of tris(2,2'-bipyridine) ruthenium(II) by nitrophenols, J. Colloid Interf. Sci. 224 (2000) 126-132.

[7] L. Zhang, P. Somasundaran, J. Mielczarski, E. Mielczarski, Adsorption mechanism of $n$-dodecyl- $\beta$-D-maltoside on alumina, J. Colloid Interf. Sci. 256 (2002) 16-22.

[8] A. Adak, M. Bandyopadhyay, A. Pal, Removal of crystal violet dye from wastewater by surfactant-modified alumina, Sep. Purif. Technol. 44 (2005) 139-144.

[9] S.b. Sun, P.R. Jaffe, Sorption of phenanthrene from water onto alumina coated with dianionic surfactants, Environ. Sci. Technol. 30 (1996) 2906-2913.

[10] D. Neupane, J.W. Park, Partitioning of naphthalene to Gemini surfactanttreated alumina, Chemosphere 41 (2000) 787-792.

[11] K. Esumi, K. Sakai, K. Torigoe, Reexamination of 2-naphthol adsolubilization on alumina with sodium dodecyl sulfate adsorption, J. Colloid Interf. Sci. 224 (2000) 198-201.

[12] A.S. Gawade, A.K. Vanjara, M.R. Sawant, Removal of herbicide from water with sodium chloride using surfactant treated alumina for wastewater treatment, Sep. Purif. Technol. 41 (2005) 65-71.

[13] C. Durkan, M.E. Welland, Nanometer scale electrical characterization of artificial mesostructures, Rev. Solid State Mater. Sci. 25 (2000) $1-28$.

[14] P. Liang, B. Hu, Z.C. Jiang, Y.C. Qin, T.Y. Peng, Nanometer-sized titanium dioxide micro-column on-line preconcentration of $\mathrm{La}, \mathrm{Y}, \mathrm{Yb}, \mathrm{Eu}, \mathrm{Dy}$ and their determination by inductively coupled plasma atomic emission spectrometry, J. Anal. At. Spectrom. 16 (2001) 863-866.

[15] A. Dyal, K. Loos, M. Noto, S.W. Chang, C. Spagnoli, K.V.P.M. Shafi, A. Ulman, M. Cowman, R.A. Gross, Activity of Candida rugosa lipase immobilized on $\gamma-\mathrm{Fe}_{2} \mathrm{O}_{3}$ magnetic nanoparticles, J. Am. Chem. Soc. 125 (2003) 1684-1685.

[16] E. Steiner, B. Kleinhappl, A. Gutschi, E. Marth, Analysis of hsp70 mRNA levels in HepG2 cells exposed to various metals differing in toxicity, Toxicol. Lett. 96/97 (1998) 169-176.

[17] J.F. Karls, E.R. Christensen, Carbon particles in dated sediments from lake Michigan, Green Bay, and tributaries, Environ. Sci. Technol. 32 (1998) 225-231.

[18] C.R. Tyler, S.R. Jobling, J.P. Sumpter, Endocrine disruption in wildlife: a critical review of the evidence, Crit. Rev. Toxicol. 28 (1998) 319-361.

[19] V.S. Wilson, C. Lambright, J. Furr, J. Ostby, C. Wood, G. Held, L.E. Gray, Phthalate ester-induced gubernacular lesions are associated with reduced insl3 gene expression in the fetal rat testis, Toxicol. Lett. 146 (2004) 207-215. 
[20] A. Fan, P. Somasundaran, N.J. Turro, Adsorption of alkyltrimethylammonium bromides on negatively charged alumina, Langmuir 13 (1997) 506-510.

[21] B. El-Eswed, F. Khalili, Adsorption of $\mathrm{Cu}(\mathrm{II})$ and $\mathrm{Ni}(\mathrm{II})$ on solid humic acid from the Azraq area, J. Colloid Interf. Sci. 299 (2006) 497503.
[22] V.K. Gupta, I. Ali, Suhas, V.K. Saini, Adsorption of 2,4-D and carbofuran pesticides using fertilizer and steel industry wastes, J. Colloid Interf. Sci. 299 (2006) 556-563.

[23] W.T. Tsai, H.C. Hsu, T.Y.Su, K.Y. Lin, C.M. Lin, Adsorption characteristics of bisphenol-A in aqueous solutions onto hydrophobic zeolite, J. Colloid Interf. Sci. 299 (2006) 513-519. 